\title{
Sexuality education for youth in Maharashtra: Yes or no?
}

International Institute for Population Sciences (IIPS)

Follow this and additional works at: https://knowledgecommons.popcouncil.org/departments_sbsr-pgy

Part of the Demography, Population, and Ecology Commons, Family, Life Course, and Society Commons, Gender and Sexuality Commons, International Public Health Commons, Medicine and Health Commons, and the Women's Health Commons How does access to this work benefit you? Let us know!

\section{Recommended Citation}

International Institute for Population Sciences (IIPS). 2008. "Sexuality education for youth in Maharashtra: Yes or no?" Youth in India: Situation and Needs Policy Brief no. 2. Mumbai: IIPS. 


\section{Sexuality education for youth in Maharashtra: yes or no?}

\begin{abstract}
Introduction
SERIOUS RESERVATIONS HAVE BEEN

EXPRESSED IN MAHARASHTRA ABOUT the sexuality component of programmes intended to build awareness of safe and healthy behaviours of school-going youth. Indeed, the state has argued against the provision of adolescent sexuality education programmes in state-run schools. The objective of this policy brief is to answer the question: is there a need for sexuality education at school and out-of-school levels in Maharashtra? Are the concerns expressed supported by evidence? Evidence is obtained from the Youth in India: Situation and Needs study conducted in Maharashtra.
\end{abstract}

\section{The study}

The Youth in India: Situation and Needs study is a sub-nationally representative study undertaken for the first time in India of key transitions experienced by young people in six states of India, including Maharashtra. The study included a representative survey of young people in both rural and urban settings. Respondents included unmarried women and men and married women aged 15-24 and, in view of the paucity of married men in these ages, married men aged 15-29. The study also included in-depth interviews with mothers and fathers of young people.

In Maharashtra, the study was conducted in 2005-06. A total of 7,570 married and unmarried young women and men were interviewed in the survey. These included 1,947 married young women, 2,541 unmarried young women, 1,065 married young men and 2,017 unmarried young men. It also included in-depth interviews with 72 mothers and fathers of young people.

The survey inquired about several issues pertinent to this discussion. It explored young people's awareness of sexual and reproductive matters, the extent of boy-girl mixing and sexual experiences of youth, parent-child communication on sexual and reproductive matters, experience of sexuality education programmes and perceptions about their acceptability. Parents were asked, likewise, about whether they had discussed sexual and reproductive matters with their children and the kinds of obstacles faced in doing so.
Are the arguments against sexuality education tenable?

Several key arguments have been made against the provision of sexuality education in Maharashtra. Our data permit an exploration of the following concerns: (a) unmarried youth are not sexually active and hence do not need sexuality education; (b) youth become aware of sexual matters once married; (c) sexuality issues are best conveyed by parents and not schools or other programmes; (d) neither youth nor their gatekeepers favour sexuality education; and (e) educating youth on sexuality will lead them to experiment with sex.

Does the evidence support the argument that unmarried youth are not sexually active and hence do not need sexuality education?

Evidence suggests that opportunities for young women and men to mix and form romantic partnerships were plentiful. For example, 30\% of young men and $24 \%$ of young women reported they had been approached by or had approached a person of the opposite sex to form a romantic liaison; and $23 \%$ of young men and $7 \%$ of young women had at least one pre-marital opposite sex romantic partner.

Sexual experience was reported by considerable proportions of young men and few young women. In total, some $16 \%$ of young men and $3 \%$ of young women reported that they had engaged in pre-marital sexual relations with a romantic or other partner. Sexual experience was more likely to be reported by rural than urban youth: $21 \%$ and $4 \%$ among rural young men and women, respectively as compared with $11 \%$ and $2 \%$, respectively among urban youth.

\section{Pre-marital romantic and sexual experiences of youth}

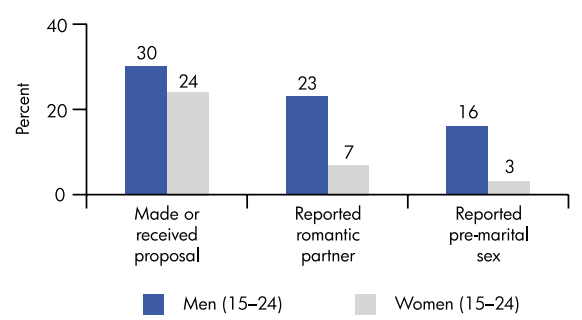


Few youth who had engaged in pre-marital sexual relations reported awareness of sexual and reproductive health matters. For example, just $14 \%$ of young men and $17 \%$ of young women reported in-depth awareness of sex and pregnancy matters, including the fact that a woman is most likely to become pregnant if she has sex halfway between her periods and that a woman can become pregnant at first sex. Likewise, while no less than three-quarters of sexually experienced young people had heard of HIV/AIDS, only $39 \%$ of young men and $30 \%$ of young women reported comprehensive knowledge of HIV/AIDS. Moreover, four-fifths of young men and women had never heard of sexually transmitted infections other than HIV/AIDS.

Sexual relations were, moreover, unsafe. For example, condom use was rarely reported by those who had ever experienced pre-marital sex: just $22 \%$ of young men and $7 \%$ of young women who had ever experienced pre-marital sex reported using a condom in all sexual encounters. Moreover, 32\% and 29\% of young men and women who had ever experienced premarital sex, respectively, reported sexual relations with more than one partner.

In short, considerable proportions of youth engaged in pre-marital sexual relations, and many more had opportunities for social mixing, developing romantic partnerships and engaging in pre-marital sex. Such evidence clearly suggests the need to equip adolescents with the information and skills to delay sexual initiation and, for those who are sexually active, to ensure that relations are safe, to counter peer/partner pressure and refuse unwanted sex, and more generally, to make informed decisions for themselves.

Does the evidence support the assertion that youth become aware of sexual matters once married? Many believed that youth become informed about sexual matters once married. Indeed, a typical perception, articulated by an urban mother was that: Girls must not be given this information [on sexual matters] before marriage; they automatically come to know after marriage.

Findings do not support this perception. They suggest, in contrast, that many young people entered marriage quite unprepared for what to expect and unaware of sexual, contraceptive and pregnancy related matters. About threequarters of married young men and women reported that they did not know what to expect of married life at the time of marriage, and over four in five reported that youth in general did not get accurate information about married life before marriage. Moreover, awareness of sexual and reproductive issues and health promoting behaviours was limited and superficial among young people. For example, half of married young men $(52 \%)$ and fewer married young women $(46 \%)$ knew that a woman can become pregnant at first sex. Just $44 \%$ of married young men and $33 \%$ of married young women reported comprehensive awareness of HIV/ AIDS, and just $22 \%$ and $15 \%$, respectively, had heard of sexually transmitted infections other than HIV/AIDS. Furthermore, 79\% of young men and just $17 \%$ of young women reported some awareness of contraception prior to marriage. Even at the time of interview, correct information about contraception was far from universal-for example, $90 \%$ of married young men and just $41 \%$ of married young women were correctly informed about condoms.

Sexuality education prior to marriage would go a long way in enabling young women-and men-to be better prepared for marriage and better equipped with the information and skills necessary for safe relations within marriage, and to enable couples to plan their families and space pregnancies if desired.

Does the evidence support the assertion that sexuality issues are best conveyed by parents? A common perception held by many is that sexual and reproductive health matters are best conveyed to youth by parents. Available evidence indicates, however, that while youth have many questions, they are unlikely to approach parents with these questions for fear that parents will become suspicious of them and mistake their curiosity for sexual experience.

Parent-child communication, in general, was limited. Even on a non-sensitive topic such as friends, communication with parents was far from universal among both young women and men. Communication between parents and adolescents on sensitive matters-reproduction or pregnancy-was extremely rare. Fewer than $1 \%$ of young men and fewer than $7 \%$ of young women in Maharashtra had ever talked to one parent or both parents about reproduction or how pregnancy occurs.

Parents themselves corroborated this lack of communication about sexual matters. Many reported that they were unwilling, uncomfortable or simply not adequately informed to 
communicate with their children on these matters. For example:

In this generation there is no need to ask anybody. Children know from the movies and newspapers about what is happening around. (Urban mother, unmarried man)

I have told her that I have no knowledge about this [sexual matters]. (Rural father, married woman)

On this topic [sexual matters], parents cannot talk to their children and children cannot talk to their parents. (Rural father, married woman)

Major sources of information on sexual matters for both young men and women were the media and friends. Among young men, 76\% reported obtaining information on sexual matters from their friends and $60 \%$ from the media; among young women, over half reported never receiving this information from any source, 16\% reported receiving this information from friends and $24 \%$ from the media. The considerable percentages of young men (39\%) who reported viewing pornographic materials through films or magazines also suggests that sizeable numbers of young men may obtain their information from these sources. Unfortunately, neither peers nor the media are especially accurate sources of information.

In short, evidence suggests that parents did not impart information on sexual matters to their adolescent children, but that adolescents sought other, less reliable sources of information to satisfy their curiosity about sexual matters.

Does the evidence support the assertion that neither youth nor their gatekeepers favour sexuality education?

Although there is a commonly articulated belief that teaching adolescents about sexual matters is unacceptable in our culture, evidence from the Youth Study raises questions about this perception. Many parents who were interviewed in-depth reportedly favoured the provision of sexuality education in school settings, for example:

If the teacher gives this education it is good. If a goldsmith pierces the ears, it will not pain. (Urban father, married woman)
In my opinion, eight subjects are already being taught in school and there will be no problem if the government introduces sex education as the ninth subject. (Rural father, married woman)

That adults were not averse to the provision of sexuality education in school settings was corroborated by the National Family Health Survey (NFHS-3), in which large proportions of young and adult women, and especially men, reported that a range of topics, including sex and sexual behaviour, contraception and the role of condoms in protecting against infection must be taught in school settings. ${ }^{\mathrm{a}}$

Young people's own perceptions about the need for sexuality education were also generally positive. The majority-over four in five-of youth in Maharashtra believed it is important for young people to have sexuality education. Of those who perceived the need for sexuality education, the majority believed that this education should be imparted to youth by the time they are 15-17; one in eight young men and two in five young women felt, however, that sexuality education should be imparted before age 15 .

Particularly notable are Youth Study findings relating to young people's perceptions about the best person to impart sexuality education to youth. Half of all young men and about two in five young women cited teachers as ideal providers of sexuality education. About one-third and one-quarter of young men and women, respectively, cited health care providers or others considered experts in this field as ideal. In contrast to preferences, just $11 \%$ of young men and $24 \%$ of young women reported that they had obtained this information from school.

Youth perceptions about the best person to provide sexuality education

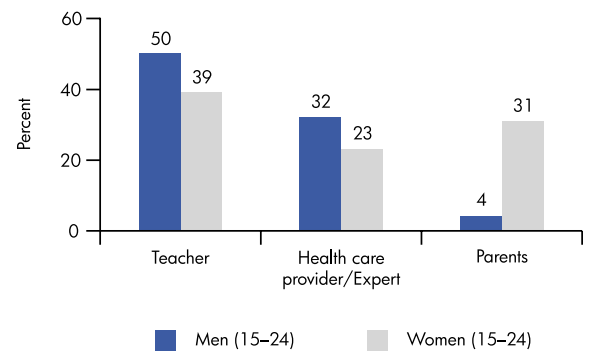

${ }^{a}$ International Institute for Population Sciences (IIPS) and Macro International. 2007. National Family Health Survey (NFHS-3), 2005-06: India, Volume 1. Mumbai: IIPS. 
Findings clearly refute the suggestion that sexuality education is unacceptable to youth and their gatekeepers. Indeed, sexuality education by teachers, experts or health care providers appeared to be acceptable to parents, and was considered ideal by overwhelming majorities of young men and women.

Does the evidence support the concern that school-based sexuality education will make young people experiment with sex?

There are few scientific evaluations of sex education programmes in India, but a review of over 80 such programmes in other developed and developing countries emphasises that sexuality education does not lead young people to engage in sex but may, in fact, make sexual relations that are undertaken, safer. ${ }^{\mathrm{b}}$

Findings from the Youth in India: Situation and Needs study in Maharashtra, while not intended to comment on the effectiveness of school-based sexuality education, do reiterate that young women and men who reported receiving school-based sex education were about as likely as those who had not received sexuality education in school settings to report that they were sexually experienced. For example, of those who had attained at least 9 years of schooling, $14-17 \%$ of both young men who had and had not received sexuality education reported pre-marital sexual activity; among young women, corresponding percentages were $2-3 \%$.

\section{Programme recommendations}

Findings suggest that many of the arguments made against the provision of sexuality education in school and non-school settings are not backed by evidence. Youth do have considerable opportunities for social mixing and developing romantic relationships; many of them are sexually active before marriage, and relations tend to be uninformed and unsafe. This, in itself, is a strong argument in favour of the provision of sexuality education for both those in school and out of school.

Other arguments are also compelling. Youth do not obtain information on sexual matters from their parents. They overwhelmingly cite the need for sexuality education and where credible sources of information are denied, they turn to other and generally less reliable sources of information such as peers, pornographic materials and other media. Finally, evidence allays fears that sexuality education may motivate youth to engage in sexual relations.

Clearly, there is a need for life skills education that both addresses young people's thirst for information about growing up and sexual matters, and provides them the skills and gender sensitivity necessary to make informed and safe life choices, including those in the sexual and reproductive arenas. Rather than arguing for banning sexuality education, findings suggest a strong rationale for providing sexuality education for school-going and out-of-school youth, for training teachers and trainers to provide information without discomfort and for parents that not only informs them of sexuality related matters but also about communicating with their adolescent children.

Suggested citation: International Institute for Population Sciences (IIPS) and Population Council. 2008. Sexuality education for youth in Maharashtra: yes or no? Youth in India: Situation and Needs 2006-2007, Policy Brief No. 2. Mumbai: IIPS.

\footnotetext{
${ }^{b}$ Kirby, D., B.A. Laris and L. Rolleri. 2005. Impact of sex and HIV education programmes on sexual behaviours of youth in developing and developed countries, Youth Working Paper No 2, FHI Working Paper Series, Research Triangle, Family Health International.
} 